San Jose State University

SJSU ScholarWorks

Spring 5-2017

\title{
An Assessment of the Associate Degree Nursing Students' Understanding of Health Literacy Concepts When Providing Health Promotion for the Diabetic Patient
}

Donna L. LeBaron

California State University, Northern California Consortium Doctor of Nursing Practice

Follow this and additional works at: https://scholarworks.sjsu.edu/etd_doctoral

Part of the Other Nursing Commons

\section{Recommended Citation}

LeBaron, Donna L., "An Assessment of the Associate Degree Nursing Students' Understanding of Health Literacy Concepts When Providing Health Promotion for the Diabetic Patient" (2017). Doctoral Projects.

64.

DOI: https://doi.org/10.31979/etd.xnn5-2sz5

https://scholarworks.sjsu.edu/etd_doctoral/64

This Doctoral Project is brought to you for free and open access by the Master's Theses and Graduate Research at SJSU ScholarWorks. It has been accepted for inclusion in Doctoral Projects by an authorized administrator of SJSU ScholarWorks. For more information, please contact scholarworks@sjsu.edu. 



\begin{abstract}
AN ASSESSMENT OF THE ASSOCIATE DEGREE NURSING STUDENTS'UNDERSTANDING OF HEALTH LITERACY CONCEPTS WHEN PROVIDING HEALTH PROMOTION FOR THE DIABETIC PATIENT
\end{abstract}

Health literacy (HL) concept deficiencies exist in undergraduate nursing curricula (Smith and Zsohar, 2011; Cornett, 2009; Jukkala, Deupree, Graham, 2009). As future nurses who will have a significant impact on client health literacy assessment, it is essential that health literacy-related content be integrated into undergraduate nursing educational curricula (Sand-Jecklin, Murray, Summers, Watson, 2010; McCleary-Jones, 2012). The prevalence of Type 2 diabetes (T2D) has significantly increased resulting in greater morbidity and mortality risks to the general public; therefore, programs for diabetes prevention, education, and health literacy assessments have become a national priority (Whittemore, Rosenberg, Gilmore, Withey, and Breault, 2013; Hemingway, Stephenson, Trotter, Clifton, and Holdich, 2015). The goal of this project is for Associate Degree nursing (ADN) students to learn to appropriately assess patient HL levels and promote healthy choices and behaviors for T2D patients. Through a qualitative exploratory approach based on Kolb's (1984) Experiential Learning Theory, this project will survey students' experiences after they have both assessed and then provided health promotion concepts to T2D patients.

\title{
Donna LeBaron
}

May 1, 2017 



\title{
AN ASSESSMENT OF THE ASSOCIATE DEGREE NURSING STUDENTS'UNDERSTANDING OF HEALTH LITERACY CONCEPTS WHEN PROVIDING HEALTH PROMOTION FOR THE DIABETIC PATIENT
}

\author{
by \\ Donna L. LeBaron, DNP, FNP-BC, RN
}

\author{
A project \\ Submitted in partial \\ Fulfillment of the requirements for the degree of \\ Doctor of Nursing Practice \\ California State University, Northern Consortium \\ Doctor of Nursing Practice
}

May 2017 


\section{APPROVED \\ California State University, Northern Consortium \\ Doctor of Nursing Practice:}

We, the undersigned, certify that the project of the following student meets the required standards of scholarship, format, and style of the university and the student's graduate degree program for the awarding of the doctorate degree.

Donna L. LeBaron

Project Author

Lori Rodriguez - Chairperson - Nursing

Ruth Rosenblum - Committee Member - Nursing Administration

For the University Graduate Committee:

Dean, Division of Graduate Studies 


\section{AUTHORIZATION FOR REPRODUCTION}

\section{OF MASTER'S THESIS}

I grant permission for the reproduction of this thesis in part or in its entirety without further authorization from me, on the condition that the person or agency requesting reproduction absorbs the cost and provides proper acknowledgment of authorship.

X___ Permission to reproduce this thesis in part or in its entirety must be obtained from me.

Signature of thesis author:

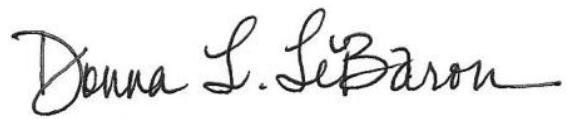




\section{ACKNOWLEDGMENTS}

I would like to both acknowledge and thank Dr. Lori Rodriguez for her time, patience, and immense support with this project. Thank you to Dr. Ruth Rosenblum for her helpful contributions. Dr. Karen Ippolito's input and time has also greatly added to my journey in completing this project and has been very much appreciated. My husband, Blake LeBaron and daughter, Natalie, and dear friend Cheryl Barnes, RN have been profound sources of encouragement during this project's production. I also wish to thank the administration at San Joaquin Delta College in Stockton, California, as well as the May 2017 ADN class for believing in and participating in the application of Health Literacy concepts. 
TABLE OF CONTENTS

Page

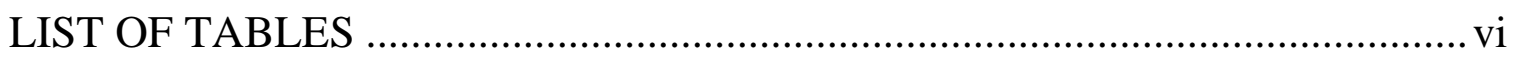

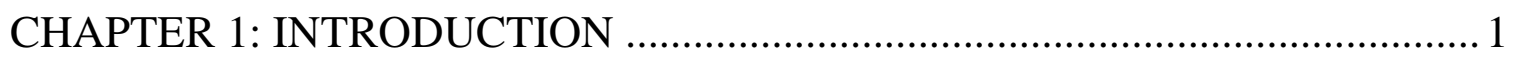

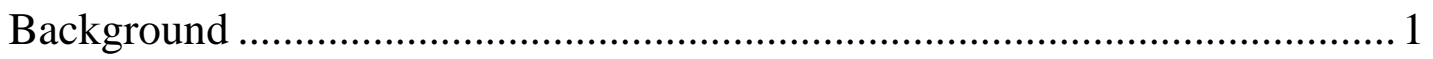

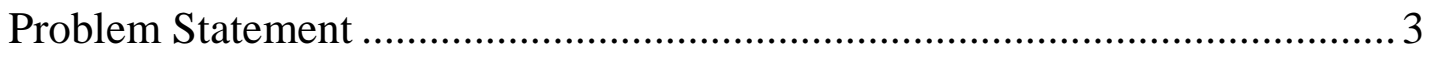

Purpose of the Project ……........................................................................... 5

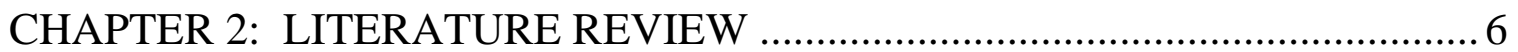

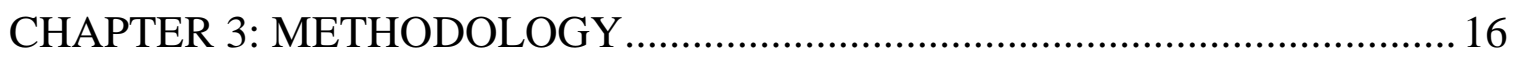

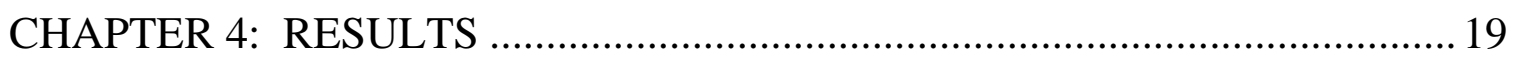

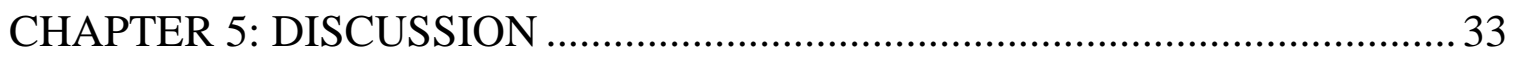

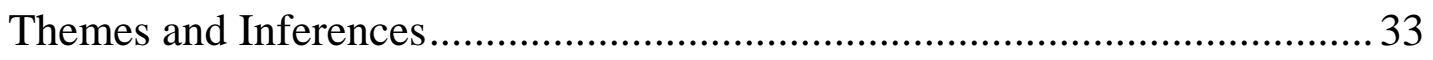

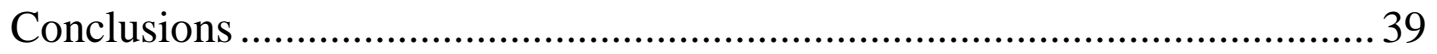

Implications for Future Practice....................................................................... 39

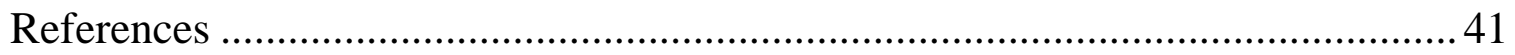




\section{LIST OF TABLES}

Page

Table \#1: Enhancements That Resulted in Increased ADN Student

Confidence When Assessing T2D HL:................................................ 21

Table \#2: Detractors [Barriers] in Confidence When Students Assessed HL in T2D Patients

Table \# 3: Did Students Feel That Their Patient Would Have Improved Health Outcomes with Using Health Promotion Strategies Tailored to

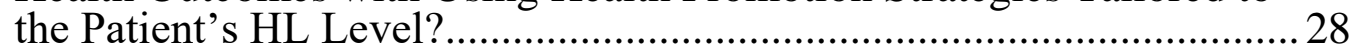




\section{CHAPTER 1: INTRODUCTION}

Health literacy (HL) concept deficiencies exist in undergraduate nursing curricula (Smith and Zsohar, 2011; Cornett, 2009; Jukkala, Deupree, Graham, 2009). As future nurses who will have a significant impact on client health literacy assessment, it is essential that health literacy-related content be integrated into undergraduate nursing educational curricula (Sand-Jecklin, Murray, Summers, Watson, 2010; McCleary-Jones, 2012). The prevalence of Type 2 diabetes (T2D) has significantly increased resulting in greater morbidity and mortality risks to the general public; therefore, programs for diabetes prevention, education, and health literacy assessments have become a national priority (Whittemore, Rosenberg, Gilmore, Withey, and Breault, 2013; Hemingway, Stephenson, Trotter, Clifton, and Holdich, 2015). The goal of this project is for Associate Degree nursing (ADN) students to learn to appropriately assess patient HL levels and promote healthy choices and behaviors for T2D patients. Through a qualitative exploratory approach based on Kolb's (1984) Experiential Learning Theory, this project will survey students' experiences after they have both assessed and then provided health promotion concepts to T2D patients.

\section{Background}

The U.S. Department of Health and Human Services (DHHS 2010) defines health literacy as the degree to which individuals have the ability to access, comprehend, and utilize basic health information and appropriate health care services to make informed health care choices. Health literacy directly impacts an individual's ability to effectively seek health care services, which includes filling out complex forms and finding providers. Poor patient outcomes are correlated 
with low health literacy and affect a patient's disease management, increased hospitalizations, and poor adherence to medication regimens (DHHS 2010).

Many factors can affect a client's aptitude for basic levels of health literacy, such as: communication skills of both the patient and professional; type of communication; level of knowledge being conveyed by the patient and professional; cultural concerns; demands of the healthcare system; and demands of the situation or context (DHHS 2010). Patient safety is compromised when misunderstandings regarding healthcare information arise or when a patient cannot effectively communicate his or her healthcare needs. Health care professionals should be aware of health literacy issues and assist patients in overcoming health literacy barriers to improve health literacy efficacy (Eadie, 2014).

Nutbeam (2009) posits that health literacy can be developed through education and can be assessed as a measurable outcome, recommending that health literacy assessments be administered, much like tests in school. Nutbeam (2009) proposes using individualized content and considering the context of information for each patient. Assessment outcomes should be measured for a variety of health literacy skills that reflect a person's acquisition, understanding, and application of context-specific knowledge. The overarching goals of increased self-determination and empowerment in health related decision-making and engagement is directly related to increased health literacy proficiency (Nutbeam, 2009).

Patient safety is jeopardized when a patient cannot effectively or appropriately communicate his or her healthcare needs; therefore, because of inherent safety issues, health literacy deficiencies need to be prioritized and addressed to improve patient outcomes (Eadie, 2014). Mancuso (2008) asserts that nurses are at the "forefront to assess and identify those with inadequate health 
literacy" (p. 253) and should begin to support an individual on a path of becoming health-literate.

\section{Problem Statement}

\section{Lack of Health Literacy in ADN Curriculum}

Currently, ADN programs have not formally integrated specific health literacy concepts or HL assessments into didactic or clinical curricula. Along with this curriculum oversight, literature gaps concerning HL in ADN programs presently exist.

Scheckel, Emery, \& Nosek (2010) make salient points that there is a need for faculty to design effective "instructional strategies" into the curriculum and that undergraduate nursing students showed "extraordinary" competencies in conveying health literacy concepts to patients. McCleary-Jones (2012) supports the integration of health literacy concepts into areas of nursing school curriculum that include patient communication and education.

Zanchetta et al. (2013) report that student awareness of the promotion of health literacy is "key" (p. 1026) to their patients' ability to use health knowledge, empowering students to effectively advocate for vulnerable patients. Ellenbecker, Byrne, O'Brien, and Walsh (2002) describe an on-site senior baccalaureate student nursing clinic where screening, health education, and outreach as well as referral services are provided as eliciting more positive patient outcomes for the patients with hypertension and diabetes, yet very few studies have been done to look specifically at the ADN curriculum incorporation of HL. Therefore, in looking at ADN student nurses becoming aware of $\mathrm{HL}$ assessments in regards to the T2D patient, this project is intended to begin to narrow the research literature gap about 
ADN HL topics as well as to assist future nurses in achieving optimal patient outcomes.

Prevalence of Diabetes

Diabetes mellitus type 2 (T2D) is a chronic disease that occurs either when the pancreas does not produce enough insulin or when the body cannot effectively use the insulin it produces. The prevalence of T2D is increasing at an alarming rate and is the seventh leading cause of death in the United States (CDC 2014). Diabetes results in serious health complications such as coronary artery disease, peripheral vascular disease, stroke, diabetic neuropathy, amputations, renal failure, and blindness, as well as reduced life expectancy.

Health care costs for the current diabetes epidemic (WHO 2015) have shown that $16 \%$ of hospital expenditure was for diabetic patients and for overall direct health care expenditures, a range of $2.5 \%$ to $15 \%$ of annual healthcare budgets (WHO). Additionally, from 1980 to 2004, Medicare beneficiaries with diabetes increased from 2.3 million to 5.3 million and accounted for $32 \%$ of all Medicare spending, according to the Centers for Medicare and Medicaid (Ashkenazy \& Abrahamson, 2006). Diabetes is becoming an economic burden due to its pandemic-like emergence in the last 50 years, with a primary rise in prevalence cited in the aged 67 or older age group, especially in older minority groups (Ashkenazy \& Abrahamson, 2006). Hospital admissions for the treatment of heart disease, stroke, kidney failure, and foot problems related to diabetes incur large health care costs, yet these conditions are potentially preventable given prompt diagnosis, effective treatment and health education (WHO 2015). 
Purpose of the fProject

Health literacy is an inherently consequential topic for health care professionals and especially for nurses who often provide health promotion education for patients. The research has shown that patient safety is endangered when health literacy barriers exist for patients. This project may benefit ADN students and faculty by increasing health literacy knowledge and assessments of health literacy. The need exists for ADN nursing students and faculty to be more in tune with patients' aptitudes for HL by increasing the focus on patient health literacy abilities and incorporating health literacy assessment skills into the ADN curriculum. With increased HL discernment for the nursing student, who will be a future nurse, patient outcomes should result in fewer safety issues and optimization of care overall.

The project goal will be to see if after a didactic health literacy module, ADN students feel that the information improved their health literacy assessment skills as they provide health promotion concepts to diabetic patients. The primary research questions of this study include:

1) What specific factors have helped to enhance or have detracted from the students' ability and confidence in assessing HL levels for a T2D patient?

2) Does the student feel that the T2D patient will have improved outcomes with the utilization of health promotion strategies that are tailored to the patient's level of HL? 


\section{CHAPTER 2: LITERATURE REVIEW}

Health Literacy and Nursing School Curriculum

Through a quantitative, descriptive study that consisted of a 5-item pretest and posttest of health literacy for Bachelors of Science Nursing (BSN) students, McCleary-Jones (2012) posit that health literacy concepts should be integrated into nursing curriculum to ultimately improve patient outcomes. A sample of 89 BSN participants completed the pretest and 53 finished the posttest questionnaire; a health literacy education module was presented to the students between the pretest and posttest. The 5-item test consisted of questions written at the knowledge, comprehension, and application levels to assess information on students' knowledge of health literacy (McCleary-Jones, 2012). Among the 53 participants, there was a significant improvement in the posttest mean score: 92.8 compared with the pretest mean score: $\left(t_{-10.015}=52 . P<.001\right)$. Students' understanding of health literacy concepts and importance to good patient outcomes improved after taking the posttest. A limitation for this study's methods lies in the lack of specific degree of variability expected in implementation and the ability of the design to detect such effects. McCleary-Jones gives a thorough explanation of the mechanisms by which intervention components anticipated to improve after the health literacy educational module was presented to the students.

Torres and Nichols (2014) contend, through a quantitative, cross-sectional study designed to evaluate HL knowledge and experiences of 391 ADN nursing students, that nursing programs are not adequately preparing their students with experience and instruction needed to assess or aid patients with limited health literacy skills. Health literacy embedded in nursing school curricula is considered the most advantageous time for future nurses to begin to understand, assess, and 
appropriately intervene when patient health literacy issues arise (Torres \& Nichols, 2014). The authors conclude that patients will greatly benefit from the reinforcement of health literacy concepts included throughout the ADN program as deficiencies in patient understanding of health information are noted and mitigated by students who will soon be registered nurses and have become competent in health literacy assessment modalities (Torres \& Nichols).

Zanchetta et al. (2013) conducted a qualitative pilot study in a Canadian undergraduate nursing degree program that examined students' understanding and sensitivity to health literacy concerns with regard to perceived health literacy barriers within organizational structures. Written student feedback was further obtained from students for possible curriculum modifications geared to promote student health literacy skill development. With a sample size of $16,(\mathrm{~N}=16)$, senior nursing students participated on a voluntary and unpaid basis with participants initially invited by email. Three, one-time individual interviews and focus groups were conducted and audiotaped; responses were then transcribed with results coded using qualitative software ATLAS ti 6.0 and submitted for thematic analysis. Additional data were gathered from the two-page assessments in the students' academic portfolios. Student sensitivity to health literacy was documented and this sensitivity in relation to patient diversity especially, reinforced interconnectedness for assessment of health literacy and for teaching health promotion concepts. It was found that teaching hospitals provided the most efficacious environments for health promotion by students. However, lack of good role models, insufficient theoretical preparation for health teaching, and unsupportive clinical environments hindered students' performance in providing adequate assessment of patient health literacy as well as in teaching health promotion (Zanchetta et al.). 
A retrospective data analysis with a quasi-experimental design was performed by Sand-Jenklin, Murray, Summers, and Watson (2010) which involved an exploratory study of 103 students who completed pre-and post-test knowledge assessment. Paired t-test comparisons were performed on a pre- and post-10-item inventory, with an increase in mean scores from 6.5 to 8.4 after a brief health literacy educational session (Sand-Jenklin, et al., p. 5). Also, data from 94 patients hospitalized on one of the medical-surgical units at a university hospital were obtained through care plan review by which students collected health literacy assessment data, which was a component of the patient assessment database, through interviewing an assigned hospital patient. Data were coded and entered into SPSS version 17 for analysis (Sand-Jenklin, et al., p. 5). With increased knowledge and competency regarding health literacy concepts being incorporated into nursing curriculum, it is hypothesized by the authors that student nurses will benefit as future nurses in providing HL level discernment to increase patient outcomes. Additionally, the authors set forth to present findings regarding the incidence of health literacy limitations among a sample of medical-surgical patients and report their preferred behaviors to compensate for their lack of understanding of health-related information. Sand-Jenklin et al. (2010) also incorporated health literacy content into a nursing curriculum and then assessed the impact of an education session the on the students' ability to master the content and apply it in the clinical setting.

In an interpretative phenomenology study, Scheckel, Emery and Nosek (2010) undertook to study eight undergraduate nursing students in their final semester of a baccalaureate nursing program who were interviewed using face-toface, unstructured interviews. Data were collected using unstructured interviews and analyzed using hermeneutics, which refers to the process of coming (through 
interpretation) to understand and the provision of an explanation (Scheckel, Emery $\&$ Nosek, 2010). The authors of this study also sought to pose ontological questions to discover students' experiences of learning and providing patient education. Through comparisons of patient education with responses to the health literacy questions via Kruskal-Wallis analysis scores indicated significantly different responses according to education level (Scheckel, Emery, \& Nosek, p. 7). Overall, it was revealed that students possess remarkable abilities to address patient health literacy issues. Scheckel et al. (2010) suggest that faculty need to formulate novel instructional strategies to enhance and deepen students' health literacy knowledge and skill application in undergraduate programs.

In conclusion, the literature shows there is an imperative need for emphasis on health literacy topics in undergraduate nursing programs. McCleary-Jones (2012) demonstrates the importance of including HL in nursing curricula; SandJecklin et al. (2010) believe nursing students are capable of identifying patient health literacy levels. Zanchetta et al. (2013) detailed how unsupportive environments hindered the occurrence of health literacy assessments among nursing students; along the same lines, Torres \& Nichols (2014) contend that inadequate amounts of health literacy instruction exist for ADN students. Scheckel, Emery, \& Nosek (2010) state that faculty need to work on designing instructional strategies that deepen students' knowledge about health literacy.

Health Literacy and Diabetes Type 2

With the extensive rise in TD2 prevalence, a national priority for diabetes prevention, education, and HL assessments have ensued (Whittemore et al, 2013; Hemingway, Stephenson et al, 2015). Though significant literature gaps concerning HL and T2D exist, some current research suggests that when nurses 
focus on HL assessments, T2D patient outcomes may be positively affected. Of special significance is the recommendation for HL assessments to become a sixth vital sign (Heinrich, 2012), thus emphasizing to providers, nurses, and patients the essential importance of ongoing HL assessments as a primary part of every patient encounter.

A longitudinal cohort study of diabetes patients was used by Sayah, Qui, and Johnson (2016) to examine the relationship between health literacy and changes in health-related quality of life (HRQL). They found that inadequate HL was independently related to declining HRQL in T2D adults, especially those with mental health issues. HL was evaluated through the use of 3 previously validated screening questions and HRQL by use of the EQ-5D-5L (EuroQuol trademark: a generic instrument for describing and valuing health) and SF-12 [physical and mental composite summary scores (PCS, MCS)] (Sayah, Qui, \& Johnson, 2016). English-speaking T2D patients over the age of 18 and were recruited over a 2-year period in Alberta, Canada. Self-administered surveys by the respondents were collected via mail and HL was assessed through the use of 3 previously validated screening questions (referred to as the Brief Health Literacy Screen "BHLS"). The following three questions were asked: "How often do you have problems learning about your medical condition because of difficulty understanding written information? How confident are you filling out medical forms by yourself? How often do you need someone (e.g., family member, friend, healthcare provider) to help you read health-related materials?" A score of 1 (for all of the time) to 5 (none of the time), with higher scores meaning lower HL and a cutoff point $\geq 9.0$ for the summative score (3-15) indicating inadequate HL (Sayah et al., 2016). The authors of this study found that though HL may not have been significantly related to changes in the EQ-5D index score, T2D patients with sufficient HL had a less 
probability to show a decline in their EQ-5D scores over time compared to those with less than par HL skills (Al Sayah et al.).

Koonce et al. (2015) conducted a randomized intervention $(\mathrm{n}=81)$ and control ( $\mathrm{n}=79)$ groups to study the generalizabilty of an individualized information prescription model to assess health literacy levels and learning styles on patients' diabetes knowledge in a community clinic setting. The researchers sought to assess effects of instructional materials geared to HL levels and learning styles on patients' diabetes knowledge in a clinic setting. This model has been previously validated and determined to be effective in informing patients about hypertension in emergency department and community health center settings (Koonce et al., 2015). Participant criteria included T2D adults, and English or Spanish-speaking individuals who were given modified versions of the Diabetes Knowledge Test (DKT) and the Subjective Numeracy Scale, along with brief health literacy and learning style assessments. Both groups were again contacted by telephone after 2 and 6 weeks to reassess diabetes knowledge which had significantly improved after exposure to educational materials geared toward patients' individualized HL levels and learning style preferences (Koonce et al.). It was found that when education that is targeted to patients' HL levels and preferences for learning styles, patients' knowledge increased significantly. The authors feel this modality can be transferred to other healthcare conditions (Koonce et al.).

A descriptive, cross-sectional study design was used by Heinrich (2012) to delineate health literacy levels of diabetic patients in a southeastern U.S. urban primary care clinic. An assessment tool, the Newest Vital Sign (NVS), developed by Weiss et al (2005) was used to measure a sample size of 54 patients, of whom $22 \%$ were Caucasian, $43 \%$ Black, and 35\% Latino/Latina. The NVS is available in both English and Spanish and consists of an ice cream container label with six 
questions where patients' abilities to understand numeracy skills as well as written and verbal information are assessed on a scale of 0 to 6 . In $65 \%$ of the study participants, low HL was found (NVS scores of 3 or less), with a mean score of 2.87 and a standard deviation of 8 (Heinrich, 2012). Due to the prevalence of low HL, ongoing assessments of patient HL need to occur in primary care settings at the patient's initial office visit and scores should be recorded in the chart, much as a sixth vital sign, and should to share with other providers. Heinrich concludes that accurate $\mathrm{HL}$ assessments play a key role in promoting optimum patient outcomes, while noting a best practice for HL assessment has not yet been established.

Hahn et al. (2015) examined connections between patient characteristics, health behaviors, and health outcomes in relation to health literacy as a potential mediator of outcomes in a cross-sectional, multivariable analysis study of underserved English-and Spanish-speaking T2D patients. Using a bilingual multimedia touchscreen to answer questionnaires, the researchers incorporated a behavioral model for vulnerable populations theoretical framework which was designed to infuse domains that are especially relevant to health concerns and health-seeking behavior in this type of population which included demographics, personal resources, perceived needs, personal health habits, and patient reported outcomes (Hahn et al., p. 5). Voluntary adult, English or Spanish-speaking T2D participants were approached in the waiting area by a bilingual research assistant at the John H. Stroger, Jr., Hospital of Cook County, Illinois during 2011-2012 and invited to participate in a multimedia patient education system about diabetic oral medication and insulin therapy. Health literacy was assessed by using a 14item short form (six prose, six document, two numeracy) from Health Literacy Assessment Using Talking Touchscreen Technology (Health LiTT; Hahn et al., 
2015), a multimedia platform with text, images, and sound (www.healthlitt.org). Participant sample size consisted of 146 English- and 149 Spanish-speaking individuals; the Spanish-speaking group had more women, lower education, more people married or in committed partner relationships, fewer insured people, more homemakers, and less prior computer experience (Hahn et al.). About one third of the participants have lived with diabetes for more than 2 years and were taking both oral medication and injectable insulin.

Hahn et al. (2015) conclude that increased diabetes self-efficacy was substantially linked to all 10 health behaviors and outcomes which were statistically analyzed in this study. Of particular note, higher self-efficacy was affiliated with better diabetes self-care, better health, and increased satisfaction with communication (Hahn et al., 2015). Bandura (2004) defines self-efficacy as the belief or confidence in one's ability to have influence over events in one's life. Therefore, the belief that one's diabetes is under control was well correlated with improved diabetes self-care, healthier eating, increased physical activity, and enhanced health overall (Hahn et al.). Overall, Hahn et al. support increasing selfefficacy in patients with chronic illnesses such as T2D as effective ways to improve health behaviors and outcomes.

Fransen, von Wagner, and Essink-Bot (2012) conducted an empirical review of the literature regarding associations between $\mathrm{HL}$, sociocognitive determinants and health actions. Three of the 11 relevant studies cited a significant positive association between HL and specific diabetes spheres of selfmanagement (Fransen, von Wagner, \& Essink-Bot, 2012). Fransen et al. (2012) contend that in order for patients to optimally perform diabetic self-management behaviors, specific knowledge and decision-making skills must be utilized across multiple domains of self-management, which requires adequate HL. Additionally, 
Fransen et al. state the two primary factors of self-efficacy (volitional determination) and practical barriers (system factors) impact the rendering of intentions into action. Gaps in the literature are reported by Fransen et al. concerning system factors with not any studies found for this pathway. Motivational and volitional determinants of self-efficacy include the domains of knowledge, beliefs and attitudes, self-efficacy, and social support (Fransen et al.). Results of this literature review show limited evidence for the correlation between HL and self-management with only three studies reporting a direct association between HL and specific domains of diabetes self-management which include recording glucose levels, treatment adherence, adjustment of insulin dose, and carbohydrate intake (Fransen et al.). The authors suggest that more studies are needed to corroborate the association between HL and diabetes self-management.

The literature suggests that a higher incidence of T2D exists in people with learning disabilities as well as seriously mentally ill people (Hemingway et al., 2015); therefore, Hemingway et al. (2015) undertook to study the pre- and posttest results of the outcomes of a workshop set up to enhance learning disability and mental health nurses' diabetic health literacy to empower these specialized nurses to more accurately convey appropriate diabetic information to service users who are at risk of, or with a diagnosis of T2D. Through a non-random (convenience) sample, which was made up of both staff and student nurses who were invited to a Day Workshop to participate in the study, a 13-item multiple choice questionnaire about diabetes was administered before and after the workshop. Each question was equally weighted (1 point each). An additional 10-item survey was given to assess workshop content and delivery, some of the questions being in Likert-style format (Hemingway et al.). Of the total 110 questionnaires that were analyzed, 62 of which were pre-workshop and 48 obtained via post-workshop activities, 30 of 
the 62 pre-workshop questionnaires were completed by student nurses and the remaining 32 were done by qualified practitioners. 22 student nurses and 26 qualified practitioners filled out the post-workshop questionnaire, for a total of 49 respondents who completed the workshop evaluation. A mean difference between pre- and post-scores was 1.14 which signifies 8.8 percentage points; a t-test found the difference to be statistically significant $(\mathrm{p}=0.004)$, with a $95 \%$ confidence interval (Hemingway et al.). Statistical and content analysis of the questionnaires showed that the educational goals of the workshop were achieved whereby specialty nurses' diabetic health literacy acumen improved. With improved diabetic health literacy, these specialty nurses can potentially increase their role as holistic caregivers (Hemingway et al.). Hemingway et al. further posit that health literacy needs to be seen more as a "corporate phenomenon" (Hemingway et al., p. 36), where organizations would implement health literacy interventions and exercises as a standard for the health care worker role, or for undergraduate nursing faculty to design and implement curriculum around increasing student knowledge and application of HL principles for their future role as nurses.

This literature review of HL and T2D leads to many salient points: principally, when nurses engage in modalities of HL assessment, they improve the diabetic patient's outcome. Studies report positive correlations to diabetic patients' quality of life with improved HL skills (Sayah et al., 2016) as well as enhanced diabetic knowledge after HL and learning assessments of T2D patients was conducted (Koonce et al., 2016). Mental health nurses felt more confident with their HL skills in imparting diabetic knowledge to the vulnerable mentally ill diabetic population in efforts to provide more holistic care (Hemingway et al., 2015). Heinrich (2012) advocates for the need to implement HL assessments at every initial primary care office visit and for HL assessments to be considered a 
sixth vital sign due to the high prevalence of low HL. Gaps in the literature exist regarding associations between HL and self-management of T2D as well as health outcomes, though higher self-efficacy (volitional determination) factors were found to play positive roles in better diabetes self-care (Hahn et al., 2015; Fransen et al., 2012).

\section{CHAPTER 3: METHODOLOGY}

\section{Study Design}

Through the use of a qualitative exploratory research method, where qualitative thematic student perceptions were obtained, this project surveyed students' experiences after they both assessed and then provided health promotion concepts to a T2D patient.

Implementation of the project began with a module which consisted of pretest of HL questions from the Agency for the Healthcare Research and Quality (AHRQ) website (see attached Quiz questions). A second part of the HL module entailed the students viewing a brief HL video (from the AHRQ site, approximately 6 minutes in length) followed by a National Patient Safety Foundation (NPSF) Health Literacy powerpoint presentation called "Leveling the Challenges of Health Literacy with Ask Me 3." To end the module, the Health Literacy Quiz was reviewed with a 5 minute discussion of the answers.

The aim of this study was to examine students' perceptions of a clinical situation after receiving information about HL having been presented in an educational module. Some of the voluntary, anonymous student participants chose to document more than one HL assessment encounter with a T2D patient. Prior to patient encounters, the student participants were issued $3 \times 5$ index cards with the two primary questions printed on them where students' anonymous perceptions 
will have been written. The index cards were numbered from 1 to 44 . A research assistant (RA) was utilized on the day of the presentation, Monday, November 14, 2016, to hand out the numbered index cards and to have students sign a sheet that corresponded to the number on their (the student's) index cards which was at all times kept sealed and kept in the possession of the research assistant so that the integrity of anonymity was maintained. The data was collected on Monday, December 12, 2016, again with an RA in attendance to maintain anonymity integrity of student participants. Through a qualitative exploratory study method, data was reviewed to discover common themes mentioned by the students during their patient encounters during which T2D HL was assessed. The journal format of having students write about their specific experiences instead of a focus group discussion was chosen because it was felt that student's might feel less inhibited in writing about their experiences rather than having to discuss them in a group situation, which could be a potential significant limitation for the type of study.

\section{Kolb's Experiential Learning Theory Framework}

The method of this study is based on Kolb's Experiential Learning Theory (ELT) which is a structured and cyclical theoretical framework that describes the learning process as emanating from an individual's direct experience (Kolb, 1984). Kolb (1984) additionally describes a four-stage learning cycle that incorporates different learning styles: (1) the Abstract Conceptualization Stage, where the learner is exposed to new concepts; (2) the Active Experimentation Stage, where new knowledge is applied; (3) the Concrete Experience Stage, where the learner encounters a new experience; and (4) the Reflective Observation Stage, where the learner reconciles new knowledge with the actual experience. 
It was felt that Kolb's ELT was appropriate for this research project because this study's structure and steps seamlessly coincided with Kolb's four ELT stages. To recap the format of this HL project in relation to Kolb's Theory: the students were first presented with a didactic HL module (Abstract Conceptualization Stage); second, the students were asked to prepare for their T2D patient interview to assess the patient's HL level (Active Experimentation Stage); next, students fully engaged in a patient interview (Concrete Experience Stage), and lastly, students wrote their perceptions about the patient encounter (Reflective Observation Stage).

Participants and Permission

A sample size of 22 third-semester Medical-Surgical students was utilized for this qualitative exploratory study. After instructing students through a 10 minute didactic presentation about health literacy, it was felt the students would be made aware of factors that should be taken into account when assessing a patient's level of health literacy.

The college classroom and four hospital clinical sites were the settings for this project. Institutional Review Boards (IRB) through San Joaquin Delta College (SJDC) as well as the IRB for California State University, Fresno were contacted and official permission was granted by both academic institutions to undertake this health literacy project.

Potential Study Limitations and Ethical Considerations

In utilizing nursing students as research participants, ethical sensitivity was ensured because students are in a vulnerable position to the power differential between them and faculty (Ridley, 2009). Ridley (2009) discusses ethical principles of autonomy, non-maleficence, beneficence, veracity, and justice with 
respect to student participants for research studies. Because most IRBs recognize college students as vulnerable research participants, there has been increased awareness for researchers to adhere to stricter guidelines to assure ethical sensitivity; so the challenge remains for nurse educators and researchers to be cognizant of ethical sensitivity when conducting research with students (Ridley).

The power differential between students and this researcher as a faculty member who possibly grades the student may create a limitation of this study's veracity on the part of the student. In order to circumvent any potential problems of this nature, it was incumbent upon this researcher to inform the students beforehand that this project is voluntary and the students' performance of carrying out the project tasks will not factor into the students' grade, which was done. Furthermore, to avoid any potential power differential conflict between instructor and student, a research assistant was utilized to distribute and collect student responses and students were informed to not write their names on their responses in order to keep student impressions anonymous to the primary researcher.

\section{CHAPTER 4: RESULTS}

This qualitative exploratory study was developed to address the lack of health literacy awareness in ADN curriculum for nursing students. After having viewed a module and taken a pre- and post-test on HL concepts, twenty-two $(n=22)$ third semester Medical-Surgical students anonymously wrote about their perceptions regarding HL concepts after having provided health promotion teaching to T2D patients in the clinical setting.

Two questions were utilized for the student participants to answer. The first question concerned specific factors which have helped or hindered the student's ability and confidence in assessing HL levels. The second question 
asked if the student feels there will be improved patient outcomes with patienttailored health promotion strategies. Student perceptions were varied, yet common themes emerged which may reinforce the need for ADN faculty to formally incorporate HL concepts into future ADN curriculum.

The following tables contain actual quotes and major themes garnered from the text of student perceptions after students interacted with T2D patients in the clinical setting. Tables 1 and 2 represent answers to the following question: "What specific factors have helped to enhance [Table \#1] or detract [Table \#2] from your ability and confidence in assessing HL for a Type 2 Diabetic patient?" Table \#3 shows students' viewpoints and inferences related to the second question: "Does the student feel that the T2D patient will have improved outcomes with the utilization of health promotion strategies that are tailored to the patient's level of HL?" 
Table \#1: Enhancements That Resulted in Increased ADN Student Confidence When Assessing T2D HL:

\begin{tabular}{|l|l|}
\hline \multicolumn{1}{|c|}{ Student Responses } & Themes From Quotes \\
\hline \#2: "Communication skills" & \\
\#4: "Reviewing the material to put in & \\
layman's terms, so the pt. can understand. & Effective Communication/Trusting Rapport \\
Build a rapport with pt." & \\
\#23: "Asking questions to pt. about the & \\
subject helped guide me with pt.'s \\
knowledge.
\end{tabular}




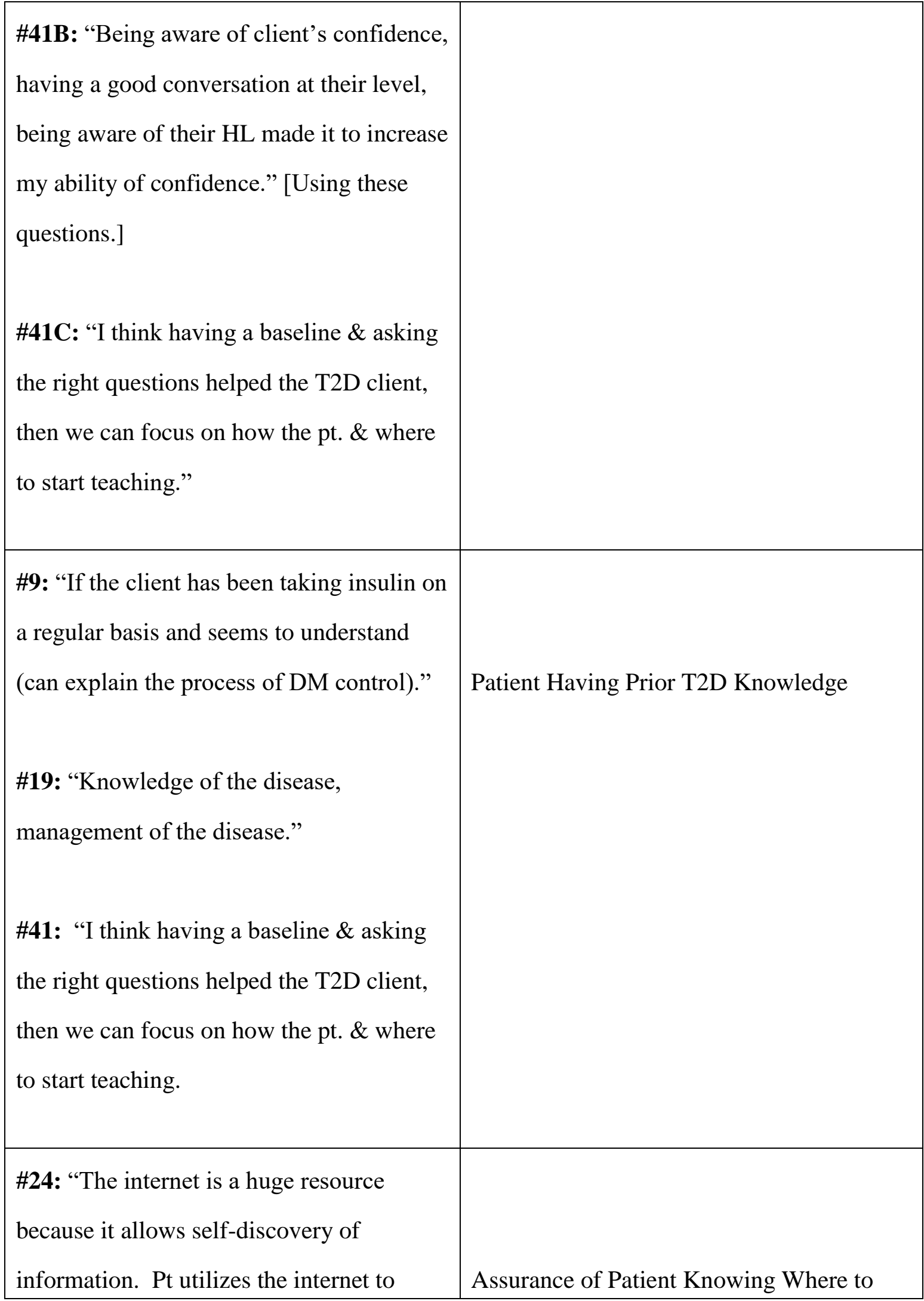




\begin{tabular}{|c|c|}
\hline $\begin{array}{l}\text { research any questions she has about: } \\
\text { changing meds, altering sliding scale, } \\
\text { symptoms, or issues." }\end{array}$ & Get T2D Health Information \\
\hline $\begin{array}{l}\text { \#27: “Asking the pt.'s baseline knowledge } \\
\text { about their disease and how they have been } \\
\text { trying to control it. The pt. knew exactly } \\
\text { what caused their T2D and what they } \\
\text { needed to do to control it. He knew to } \\
\text { check blood glucose levels and knew they } \\
\text { should be between } 70-110 \text {. I am very } \\
\text { sure the pt. can take an active role in } \\
\text { controlling their T2D. They also } \\
\text { mentioned buying a cook book to try to eat } \\
\text { healthier." }\end{array}$ & $\begin{array}{l}\text { High Level of Patient Self-Efficacy with } \\
\text { T2D Self-Management }\end{array}$ \\
\hline $\begin{array}{l}\text { \#32: "Patient's willingness to participate." } \\
\text { \#43: "Pt knew D2 process of their T2D, } \\
\text { how much insulin should be used based on } \\
\text { FSBG, and understood importance of } \\
\text { decreasing processed food diet and } \\
\text { exercise." }\end{array}$ & \\
\hline $\begin{array}{l}\text { \#4: “Assessing pt.'s health background. } \\
\text { Patient had a high school education, so I }\end{array}$ & \\
\hline
\end{tabular}


gave written info \& drew a picture for pt.
of how T2D works."

Student Awareness of Patient HL Level and/or Patient's T2D Knowledge

\#12: “Knowing the patient's history and background prior to the interaction."

\#14: "Assessing their knowledge of the disease process and if any barriers exist in self-care. Signs/symptoms of hypoglycemia and hyperglycemia."

\#25: “Assess the patient's knowledge base and reviewing chart prior to speaking to patient to obtain consistency in $\mathrm{t} / \mathrm{x}$."

\#27: “Obtaining a baseline data of pts understanding of disease."

\#34A: "Specific educational courses related to literacy"

\#34B: "Assuming everyone is struggling with HL helps eliminate the chance of misinterpreting on an individual's HL level." 


\begin{tabular}{|l|l|}
\hline \#40: "Factors that have helped me assess & \\
my patient for the HL are asking them & \\
questions regarding treatment and & \\
assessing non-verbal ques of confusion or & \\
hesitation to speak about it. & \\
\#40: "Assuming everyone is struggling & \\
with HL helps eliminate the chance of & \\
misinterpreting on an individual's HL & \\
level." & \\
\#34: “An easier determination of patient's & \\
understanding was made after an & \\
\#1: "Being more enthusiastic with the & \\
teach-back strategy." & \\
\#16B: "Giving the patient the ability to & Use of "Teach Back" Method \\
the teach-back process." & \\
\hline
\end{tabular}




\begin{tabular}{|c|c|}
\hline $\begin{array}{l}\text { explanation based on their 'teach back' } \\
\text { was given." }\end{array}$ & \\
\hline $\begin{array}{l}\text { \#23: "Knowing more about the subject } \\
\text { gave me confidence to talk more about it } \\
\text { with DM patient." } \\
\text { \#28: "Knowing how T2D works and is } \\
\text { managed made it easier to educate on } \\
\text { interventions to help patients with their } \\
\text { disease." }\end{array}$ & Student Knowledge of T2D \\
\hline
\end{tabular}

Table \#2: Detractors [Barriers] in Confidence When Students Assessed HL in T2D Patients

\begin{tabular}{|l|l|}
\hline \multicolumn{1}{|c|}{ Student Responses } & \multicolumn{1}{c|}{ Themes From Quotes } \\
\hline $\begin{array}{l}\text { \#12: “...As well as being able to } \\
\text { communicate in the patient's primary } \\
\text { language." }\end{array}$ & Existing Language Barriers \\
\hline $\begin{array}{l}\text { \#19: "Knowledge of the disease, } \\
\text { management of the disease.” }\end{array}$ & \\
$\begin{array}{l}\text { \#24 (Inference): “Understanding of the } \\
\text { physiology of the organs involved, and } \\
\text { having explanation of meds action." }\end{array}$ & Poor Patient Understanding of T2D \\
\hline
\end{tabular}




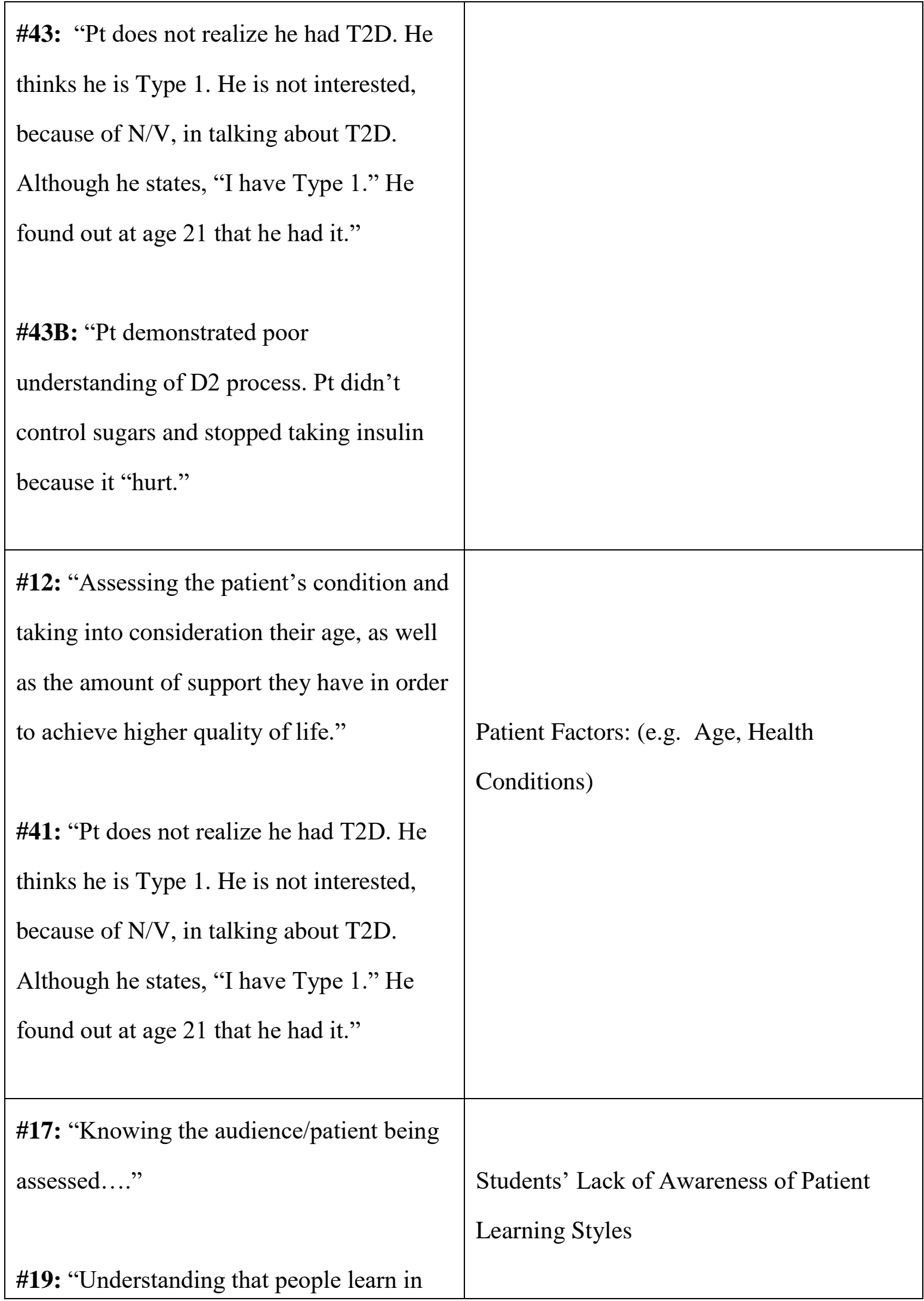




\begin{tabular}{|l|l|}
\hline different ways.” & \\
\hline \#17: "Mental state of student." & Student Anxiety About Patient Encounter \\
\hline
\end{tabular}

Table \# 3: Did Students Feel That Their Patient Would Have Improved Health Outcomes with Using Health Promotion Strategies Tailored to the Patient's HL Level?

\begin{tabular}{|l|l|}
\hline \multicolumn{1}{|c|}{ Student Responses } & \multicolumn{1}{|c|}{ Themes From Quotes } \\
\hline \#1-1: "Voice in care: Yes, the patient was & \\
very happy to have a voice in his care." & \\
\#4-2: "Patient answered directly that they & Evidence of Improved Patient Outcomes \\
would have improved care." & When Assessing HL Levels \\
\#9: "Patient admits to needing additional \\
teaching to help him stay on track" \\
$\begin{array}{l}\text { \#31-1: "Yes, as I answered questions in an } \\
\text { easier way to understand manner. I was } \\
\text { able to dispel many misconceptions related } \\
\text { to self-care and managing their T2D." }\end{array}$ \\
$\begin{array}{l}\text { \#31 -2: "Yes, after educating the pt and } \\
\text { asking them to reteach me what was just } \\
\text { taught, I could recognize } \\
\text { misunderstandings }\end{array}$
\end{tabular}




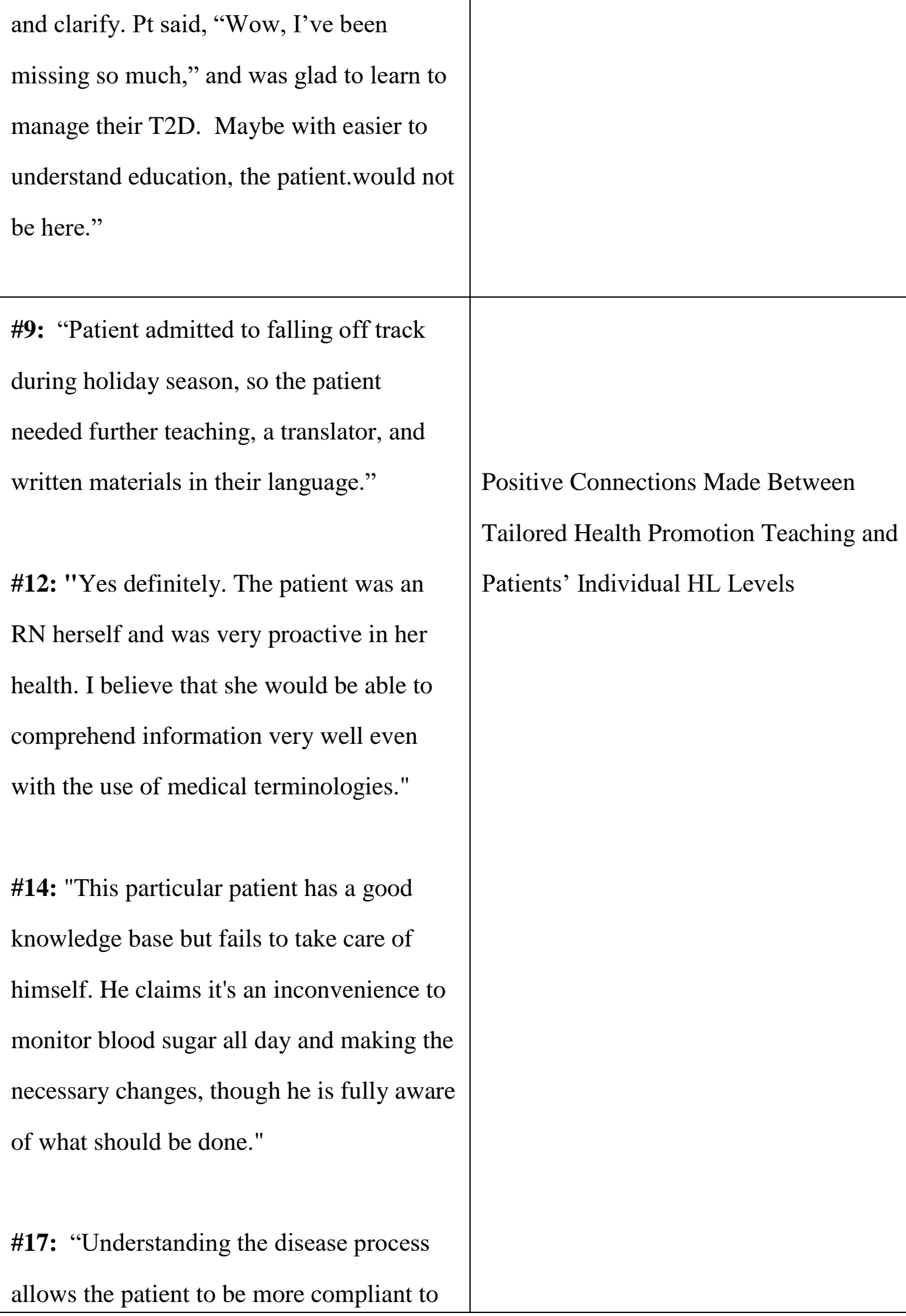

\#14: "This particular patient has a good knowledge base but fails to take care of himself. He claims it's an inconvenience to monitor blood sugar all day and making the necessary changes, though he is fully aware of what should be done."

\#17: "Understanding the disease process allows the patient to be more compliant to

Positive Connections Made Between

Tailored Health Promotion Teaching and Patients' Individual HL Levels 


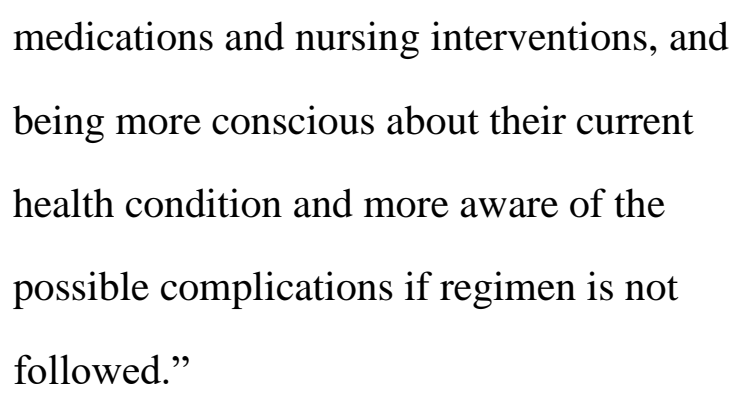

\#24-1: “This T2D pt. utilizes most health promotion strategies already. She has had T2D for $30+$ years. She admits that she now knows more than some of her doctors do regarding new drug treatments to try. I believe that if this patient was utilizing all of her strategies that she would have less exacerbations. This pt. should focus on gaining understanding of lifestyle modification strategies, as much research has been done regarding exercise and diet plans for T2D pt.'s. This pt.'s health factor is "very sure."

\#24-2 "Yes, when a patient is motivated by their condition, their desire to learn is enhanced. This pt. would love tailored learning to further her knowledge of her illness. Acting on this knowledge will be hard for her, she admits. Health factor is 
"somewhat sure."

\#27-2 "I'm somewhat sure this pt will have improved outcomes. She seemed to have some decent knowledge about illness and what she shouldn't eat, but seemed to not have any interest in monitoring daily glucose levels. She was very set in her mind that the machine gave her incorrect readings. There was not much to do to change her opinion."

\#27-1: "Yes I do. I believe with the correct knowledge and understanding of their disease and what they need to do to control their illness, the pt will have a better chance and controlling their illness. The pt.'s level of knowledge was very good and they seemed willing to do the things needed to control the illness. "I'm very sure."

\#28-2: "Yes. Often, information is given to a pt but they aren't aware of its meaning. It's easy to forget how little the general population understands about medicine, so tailoring knowledge to the way a pt. can 


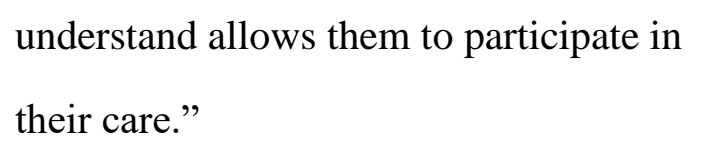

41 -\#1: "This patient would benefit from health promotion strategies such as a return demonstration. When he is feeling better, information needs to be given to him to make him aware that his condition is modifiable and manageable."

\#41-\#2: "Yes, the patient has a high HL. She understands the instructions, has been taking care of her DM for 10 years. She is interested in taking care of her health, but says she will struggle during the holidays. The patient doesn't mind reading instructions - likes books. With the questions asked of the patients, it is easy to meet her "understanding" or HL needs. However, patient is non-compliant or not taking care of herself. Pt is 35 , has neuropathy and diminished vision."

\#41-\#3: “Asking the right questions to evaluate patient's knowledge and ability helped a lot. I knew the baseline - where to 
start with pt. education."

\section{CHAPTER 5: DISCUSSION}

Themes and Inferences

Health Literacy Assessment Confidence-Boosting Modalities

In response to the question concerning enhancements that boosted students'

self-confidence, students cite communication skills such as open-ended

questioning and use of understandable layman's language, as well as watching the patient giving a "teach back" session as valuable ways to augment their abilities to assess patient HL. Additionally, respondents felt these techniques also helped to build a trusting rapport between the student and patient. The ability to appropriately use and guide a patient through health promotion teaching was also improved when the students could provide written handouts for the patient. Other confidence-boosting factors mentioned by the students included those encounters where patients demonstrated having prior knowledge of T2D and also with patients who seemed to be well-informed about where they could obtain additional information, such as from the Internet. The increased knowledge on HL helped the students to engage in appropriate patient teaching strategies.

\section{Enhanced Communication}

In the lecture classroom HL training module, a focus on various communication skills to utilize with patients for improved HL assessment was presented. The responses from this cohort of student respondents demonstrate that the introduction or review of effective communication techniques enhances the students' performance. Some of the particular skills that the students felt had been 
either introduced or enhanced in the student-patient interview were remembering the importance of speaking in a way that a patient can understand. As one student said: "Reviewing the material to put in layman's terms, so the pt. can understand," and from another student, "Using a simple and layman's vocabulary." Additional communication skills that enhanced the students' ability in the patient HL assessment interviews were remembering to ask questions in understandable terms and knowing in particular what types of questions to ask. A student respondent wrote: "Asking the patient about the subject helped guide me with the patient's knowledge level." One student stated "Asking open-ended questions helped begin the assessment," demonstrating that the student had recognized this as an important tool for assessing the patient's health literacy.

Improved Student/Patient Relationship.

Overall, many of the students noted that as their communication skills with the patient improved, their relationship with the patient was also strengthened. Once a positive and trusting relationship was established between the student and patient, both individuals felt more receptive to beginning the interview, where improving the nursing student's ability to assess the T2D patient was reportedly enhanced. Furthermore, when several students were assured that the patient was clear about what T2D issues needed to be discussed, it was felt that an enhanced, helpful relationship with patient ensued as evidenced by this student quote: "I think having a baseline and asking the right questions helped the T2D patient, then we can focus on how to help the patient and where to start teaching." Another student wrote that understanding "where the patient was coming from as well as having the conversation at the patient's level of understanding" increased the student's confidence. 
Benefits of Handout Materials

Several students attested to the benefits of written information or pamphlets being available to give to the patient during the student/patient interview. Along these same lines, student HL assessment acumen appeared to improve when available T2D informational handouts prompted engaged student/patient "verbal teaching" sessions, during which the student was able to simultaneously ascertain the patient's cognitive processing of T2D health promotion information as well as HL levels. As one student wrote: "Ensuring that the patient is involved with the teaching and having handouts (resources) available." The availability of printed informational material seemed to be advantageous for both students and patients as it boosted student confidence in HL assessments and in relaying T2D principles for the student; while patients can review the written information at a later time to ensure their comprehension of important T2D concepts.

\section{Patients' Prior T2D Knowledge Level}

Some nursing students felt that their confidence in assessing T2D HL levels was increased when patients had prior knowledge of the diabetes and how to manage it, which can be inferred by this student statement: "the patient has been taking insulin on a regular basis and seems to understand (can explain the process of DM control)." Additionally, students appeared to make some astute correlations regarding patient knowledge-level, patient self-efficacy, and patient HL levels as exemplified by the following quote: "When asking the patient's baseline knowledge about their disease and how they have been trying to control it, the patient knew exactly what caused their T2D and what they needed to do to control it. He knew to check blood glucose levels and knew they should be 
between $70-110$. I am very sure the patient can take an active role in controlling their T2D. They also mentioned buying a cookbook to try to eat healthier."

\section{T2D Information Accessibility}

With regard to the relationship between high levels of T2D selfmanagement and possible higher HL level is the student reporting of patients' abilities and knowledge to access the Internet for additional T2D knowledge. An inference can be made that student participants felt increased confidence in assessing a patient's HL level when patients verbalized a reliable means in accessing T2D information as depicted in this student quote: "The internet is a huge resource because it allows self-discovery of information. Patient utilizes the internet to research any questions she has about: changing meds, altering sliding scale, symptoms, or issues."

Students' T2D Knowledge Levels and Utilization of Teach Back Method Two additional HL assessment confidence-enhancing modalities reported by student respondents included the significance of students feeling secure in their own T2D knowledge base as well as the utilization of a "teach back" method for closure of the interview. The following quotes give credence to students considering their own knowledge as paramount to feeling confident in assessing HL levels in patients: "Knowing more about the subject gave me confidence to talk more about it with DM patient," and "Knowing how T2D works and is managed made it easier to educate on interventions to help patients with their disease." Furthermore, several students lauded the traditional teach back method as a way to confidently appraise a patient's understanding of concepts and potentially, HL levels, as depicted by these two students' declarations: "Giving the patient the ability to demonstrate knowledge about T2D is key;" and, "Reviewing 
meds prior to discharge for the teach-back process" helped the student to evaluate the patient's level of HL. An additional quote that emphasized how the "teach back" method streamlined the HL assessment and health promotion teaching exercise is as follows: "An easier determination of patient's understanding was made after an explanation based on their 'teach back' was given."

Detractors to Students' Ability and Confidence When Health Literacy Was Assessed Patient Language Barriers and Other Factors

Students cited patient language barriers, patient age, and poor health conditions as challenges to effectively assessing a patient's HL level. The following quotes attest to students encountering patient-related obstacles: "The patient did not realize he had T2D and could not talk because of nausea and vomiting," and "Assessing the patient's condition and taking into consideration their age, as well as the amount of support they have in order to achieve a higher quality of life" underscore several of the challenges students experienced when attempting to measure a patient's HL level.

Poor Patient Understanding of T2D

Patient misunderstanding of T2D disease process was another area that presented difficulties for students to carry out a successful HL assessment. One student wrote [the patient had limited] knowledge of the disease and management of the disease" as being a specific detractor to an effective student-T2D interaction. Similarly, another student conveyed that [the patient did not seem to have an] "understanding of the physiology of the organs involved, and having to explain the actions of the medications" as being of concern when attempting to give health promotion teaching while assessing for a patient HL level. 
Students' Lack of Knowledge of Patient Learning Styles, TD2, and Student Anxiety

Additional challenging areas mentioned by students dealt with the students' assessment and teaching acumen as well as student anxiety with the patient interaction in general. The following two quotes underscore the student's lack of confidence when attempting to provide health promotion teaching: [It may have helped to] "know the audience/patient being assessed," and [having more insight into] "understanding that people learn in different ways" may have increased students' effectiveness with HL assessments. Another student wrote that having had more "research about T2D disease process" would have strengthened the student's foundation of knowledge to teach about T2D concepts. Along these same lines, the student's personal feelings of anxiety came into play when the "mental state of the student," was mentioned as feelings of inadequacy surfaced during a first attempt at communicating and applying the HL assessment process during an actual student-patient encounter. Due to nursing students' limited experience with providing health promotion teaching to TD2 patients, feelings of inadequacy could naturally arise for the student nurse.

Students' Perceptions about Improved Patient Outcomes Related to HL Assessment Show Evidence of Improved Outcomes

Several student quotes indicate potential improved patient outcomes with the undertaking of a patient HL assessment. A particularly germane student quote is as follows: "Yes, after educating the patient and asking them to reteach me what was taught, I could recognize misunderstandings and clarify. The patient stated, 'Wow, I've been missing so much,' and the patient was glad to learn more to manage their T2D. Maybe with easier to understand education, the patient wouldn't be here." Another student wrote: "Patient admits to needing additional teaching to help him stay on track." 
Positive Connections Made Between Tailored Teaching and HL

Through the application of HL assessments, the students seemed to make some salient realizations. Students positively connected the significance of assessing HL levels and tailoring health promotion teaching to the patients' HL levels. Moreover, students gained a measure of confidence in utilizing HL concepts to enhance patient-centered problem solving skills which may result in improved patient outcomes. Likewise, the students realized the overall relevance and significance for assessing HL levels in patient interaction and care situations.

\section{Conclusions}

The findings from this project indicated that students' confidence and abilities were raised in performing HL evaluations as well as in the provision of health promotion teaching for the T2D patient with the utilization of HL concepts and effective communication skills. Furthermore, the findings support that improved nursing student knowledge about HL and assessment of patient HL levels may enhance patient outcomes.

\section{Implications for Future Practice}

Health literacy conceptual knowledge and assessments should be at the forefront of patient assessments for all clinical nurses. To augment clinical nurse HL assessments, proficient training about HL topics should be formally addressed as a part of nursing school curricula, since student nurses will be our future frontline practicing nurses. Additionally, the need exists for routine $\mathrm{HL}$ assessments to become an integral assessment modality for all nurse-patient interactions where documentation of HL levels would be mandatory to improve consistency of patient care and subsequent patient outcomes. To accurately assess HL, intervene in a patient care situation, or to provide health information, nurses should adhere 
to effective communication strategies shown to optimize individual patient health teaching consistent with that specific patient's HL level. Lastly, it is hoped that more studies about HL in relation to nursing school curriculum will ensue in an effort to mitigate the existing current academic gaps found in nursing school pedagogy regarding HL concepts. 


\section{REFERENCES}

Agency for Healthcare Research and Quality (AHRQ). (2015) Retrieved from: http://www.ahrq.gov/professionals/quality-patient-safety/qualityresources/tools/literacy-toolkit/healthlittoolkit2-tool3d.html.

American Diabetes Association (ADA). (2013). The costs of diabetes. Retrieved from http://www.diabetes.org/advocacy/news-events/cost-of-diabetes.html.

Ashkenazy, R., \& Abrahamson, MJ. (2006). Medicare coverage for patients with diabetes: A national plan with individual consequences. Journal of Internal Medicine, 21(4): 368-392.

Bandura, A. (2004). Health promotion by social cognitive means. Health Education \& Behavior, 31(2), 143-164.

Bohanny, W., Wu, S. V., Liu, C., Yeh, S., Tsay, S., \& Wang, T. (2013). Health literacy, self-efficacy, and self-care behaviors in patients with type 2 diabetes mellitus. Journal of the American Association of Nurse Practitioners, 25(9), 495-502 8p. doi:10.1111/1745-7599.12017

Current Nursing Website. (2013). Health Belief Model. Retrieved from: http://currentnursing.com/nursing_theory/health_belief_model.html

Center for Disease Control and Prevention (CDC). (2014). Diabetes. Retrieved from http://www.cdc.gov/nchs/fastats/diabetes.htm.

Cornett, S. (2009). Assessing and addressing health literacy. Online Journal of Issues in Nursing, 14(3), 1.

Day, L., Turner, K., Anderson, R. A., Mueller, C., McConnell, E. S., \& Corazzini, K. N. (2015). Teaching Delegation to RN Students. Missouri State Board of Nursing Newsletter, 17(1), 5-8.

Diabetes Numeracy Test (DNT15): The shortened version at http://healthliteracy.bu.edu/documents/44/DNT15\%20rev\%20508.pd

Eadie, C. (2014). Health literacy: A conceptual review. Academy of MedicalSurgical Nurses Newsletter, 23(1), 9-13.

Ellenbecker, C., Byrne, K., O'Brien, E., \& Rogosta, C. (2002). Nursing clinics in elder housing: providing access and improving health care outcomes. Journal of Community Health Nursing, 19(1), 7-15. 
Fransen, M.;von Wagner C.;Essink-Bot, M. (2012). Diabetes self-management in patients with low health literacy: Ordering findings from literature in a health literacy framework. Patient Education and Counseling, 88(1): 44-53.

Hahn, E. A., Burns, J. L., Jacobs, E. A., Ganschow, P. S., Garcia, S. F., Rutsohn, J. P., \& Baker, D. W. (2015). Health Literacy and Patient-Reported Outcomes: A Cross-Sectional Study of Underserved English- and Spanish-Speaking Patients with Type 2 Diabetes. Journal of Health Communication, 20(2), 415. doi:10.1080/10810730.2015.1061071

Healy, A. M. (1995). Preparation of ADN and BSN nursing students for their teaching role (Order No. 9614614). Available from ProQuest Dissertations \& Theses Full Text: The Humanities and Social Sciences Collection; ProQuest Dissertations \& Theses Full Text: The Sciences and Engineering Collection. (304214062). Retrieved from http://search.proquest.com/docview/304214062? accountid=10349

Hemingway, S., Stephenson, J., Trotter, F., Clifton, A., \& Holdich, P. (2015). Increasing the health literacy of learning disability and mental health nurses in physical care skills: A pre and post-test evaluation of a workshop on diabetes care. Nurse Education in Practice, 15(1), 30-37. doi:10.1016/j.nepr.2014.08.003

Heinrich, C. (2012). Health literacy: The sixth vital sign. Journal of the American Academy of Nurse Practitioners, 24(4), 218-223. doi:10.1111/j.17457599.2012.00698.x

Huizinga, M.M., Elasy, T.A., Wallston, K.A., Cavanaugh, K., Davis, D., Gregory, R.P., Fuchs, L.S., Malone, R., Cherrington, A., DeWalt, D.A., Buse, J., Pignone, M., \& Rothman, R.L. (2008). Development and validation of the Diabetes Numeracy Test (DNT). BMC Health Serv Res, 8:96

Ishikawa, H. \& Yano, E. (2011). The relationship of patient participation and diabetes outcomes for patients with high vs. low health literacy. Patient Education and Counseling, 84(3), 393-397

Jukkala, A., Deupree, J., \& Graham, S. (2009). Knowledge of limited health literacy at an academic health center. Journal of Continuing Education in Nursing, 40(7), 298-304. doi: 10.3928/00220124-20090623-01

Kolb, D. A. (1984). Experiential learning: Experience as the source of learning and development. Upper Saddle River, NJ: Prentice Hall. 
Koonce, T. Y., Giuse, N. B., Kusnoor, S. V., Hurley, S., \& Fei, Y. (2015). A personalized approach to deliver health care information to diabetic patients in community care clinics. Journal of the Medical Library Association, 103(3), 123-130. doi:10.3163/1536-5050.103.3.004

Lisko, S., \& O'Dell, V. (2010). Integration of theory and practice: experiential learning theory and nursing education. Nursing Education Perspectives (National League for Nursing), 31(2), 106-108.

National Patient Safety Foundation Health Literacy Powerpoints. (2016).

Retrieved from:

http://c.ymcdn.com/sites/www.npsf.org/resource/resmgr/AskMe3/AskMe3_ HealthLiteracyTrainin.pdf?hhSearchTerms $=\% 22$ Leveling + and + challenges $+\mathrm{a}$ nd+health+and+literacy\% 22 .

Nutbeam, D. (2009). Defining and measuring health literacy: What can we learn from literacy studies? International Journal of Public Health, 54, 303-305. doi: $10.1007 / \mathrm{s} 00038-0050-\mathrm{x}$

Mancuso, J. (2008). Health literacy: A concept/dimensional analysis. Nursing \& Health Sciences, 10(3), 248-255 8p.

McCleary-Jones,V. (2012). Assessing nursing students' knowledge of health literacy. Nurse Educator, 37(5), 214-217.

Melnyk, B.M. \& Fineout-Overholt, E. (2015). Evidence-based practice in nursing and healthcare: A guide to best practice (3rd ed.). Philadelphia, PA; Lippincott Williams \& Wilkins (Wolters Kluwer).

Ridley, R. (2009). Assuring ethical treatment of students as research participants. Journal of Nursing Education, 48(10), 537-541 5p. doi: 10.3928/0148483420090610-08

Sand-Jecklin, K., Murray,B., Summers, B. , \& Watson, J. (2010). Educating nursing students about health literacy: From the classroom to the patient bedside. Online Journal of Issues in Nursing, 15(3), 1E.

Scheckel, M., Emery, N., \& Nosek, C. (2010). Addressing health literacy: The experiences of undergraduate nursing students. Journal of Clinical Nursing, 19(5-6), 794-802. doi:10.1111/j.1365-2702.2009.02991.

Sayah, F.A., Qiu, W. \& Johnson, J.A. (2016). Health literacy and health-related quality of life in adults with type 2 diabetes: a longitudinal study. Quality of Life Research, 25: 1487. doi: 10.1007/s11136-015-1184-3 
Smith, J. A., \& Zsohar, H. (2011). Teaching health literacy in the undergraduate curriculum: Beyond Traditional Methods. Nursing Education Perspectives, 32(1), 48-50. doi:10.5480/1536-5026-32.1.48

Sullivan, L.M. (2015, June 15). An Evaluation of Health Literacy Education: Effects on Cultural Competence, Knowledge, and Attitudes of Associate Degree Nursing Students. Virginia Henderson Global Nursing e-Repository. Retrieved from http://www.nursinglibrary.org/vhl/handle/10755/556956

Torres, R. \& Nichols, J. (2014). Health literacy knowledge and experiences of associate degree nursing students: A pedagogical study. Teaching and Learning in Nursing, 9, 84-92.

U.S. Department of Health and Human Services (DHHS). (2010). Healthy people 2020. Health Communication and Health Information Technology. Retrieved from http://health.gov/communication/literacy/quickguide/factsbasic.htm.

Weiss, B, Mays, M., Martz, W., Castro, K., DeWalt, D., Pignone, M., Mockbee, J., \& Hale, F. (2005). Quick assessment of literacy in primary care: The new vital sign. Annals of Family Medicine, 3, 514-522.

Whittemore, R., Rosenberg, A., Gilmore, L., Withey, M., \& Breault, A. (2014). Implementation of a Diabetes Prevention Program in Public Housing Communities. Public Health Nursing, 31(4), 317-326. doi:10.1111/phn.12093

World Health Organization (WHO). (2015). Diabetes fact sheet. Retrieved from: http://www.who.int/mediacentre/factsheets/fs236/en/.

Zanchetta, M., Taher, Y., Fredericks, S., Waddell, J., Fine, C., and Sales, R. (2013). Undergraduate nursing students integrating health literacy in clinical settings. Nurse Education Today, 33, 1026-1033. doi:

10.1016/j.nedt.2012.05. 




